\title{
Offshore hydrogen production from wave energy
}

\author{
Álvaro Serna*, Fernando Tadeo \\ Universidad de Valladolid, Departamento de Ingeniería de Sistemas y Automática, C/Doctor Mergelina s/n 47011, \\ Valladolid, Spain
}

\section{A R T I C L E I N F O}

Article history:

Received 8 February 2013

Received in revised form

19 April 2013

Accepted 20 April 2013

Available online 22 May 2013

Keywords:

Offshore systems

Wave energy

Electrolyzers

Off-grid systems

\begin{abstract}
A B S T R A C T
The aim of this paper is to present and evaluate a proposal for designing an off-grid offshore electrolysis plant powered by wave energy. This plant includes PEM electrolyzers, a Reverse Osmosis system to produce water with adequate conductivity, a compression unit to store the hydrogen for transport, and batteries for temporary storage of electricity for short-time balances. First, the systems that compose the proposed plant are justified and described. Then a proposal for sizing these subsystems is given, based on using buoy-measured data at the expected location and simple mathematical models of the different sections of the plant. Finally the performance of the plant in a specific location is tested in detailed by using measured data, studying the influence of sizing on the expected performance.

Copyright @ 2013, Hydrogen Energy Publications, LLC. Published by Elsevier Ltd. All rights
\end{abstract} reserved.

\section{Introduction}

This paper refers to a renewable energy offshore plant to produce hydrogen currently under development. It is well known that hydrogen is a clean energy carrier independent of energy sources [1]. The full benefits of hydrogen will be obtained when is produced from renewable energy sources. Different renewable energy sources have already been studied for electrolyzation, such as wind [2,3] and solar energy [4,5]; the feasibility of these sources to produce hydrogen has been demonstrated, with the main drawback the variability of these sources (see, for example [5], for a detailed feasibility and economical study), and the significant cost of solar hydrogen [6].

There are some published works on using reverse osmosis to obtain hydrogen from seawater, involving wave energy for generating the energy for the process $[7,8]$. There are even patents available that take into account this idea $[9,10]$.
This paper concentrates on offshore systems: the source considered in this work is wave energy as wave converters provide lower variability in the energy production in comparison with other sources [11]. Offshore power links are known to be significantly expensive [12], so the system is here assumed to be fully isolated from the grid: it is parallel to the grid independent wind-hydrogen generation presented in [6]. Thus, power consumption adapts to power production by connecting or disconnecting sections of the electrolyzation plant (following a Smart Grid approach for the microgrid in the plant), and using a temporary storage of electricity for shorttime balances and increase of autonomy (that is a relevant issue in offshore installations). Automatic cleanings and maintenance operations are scheduled in the sections that are temporarily disconnected, to improve overall efficiency. Compared with previous proposals [8-10], this paper concentrates on using commercially available components that are already tested in the marine environment. Special

\footnotetext{
* Corresponding author. Tel.: +34 983184859.

E-mail addresses: alvaro.serna@autom.uva.es, alvarosercan@hotmail.com (Á. Serna). 0360-3199/\$ - see front matter Copyright @ 2013, Hydrogen Energy Publications, LLC. Published by Elsevier Ltd. All rights reserved. http://dx.doi.org/10.1016/j.ijhydene.2013.04.113
} 
attention is given to the modeling for sizing of the components, the production of low-conductivity water for the electrolysis and the control system.

In summary, the system presented here is composed of a primary energy source, namely wave energy, which provides electricity in order to produce hydrogen using PEM electrolyzers. Water for these electrolyzers is obtained from seawater using membrane technologies based on Reverse Osmosis (RO [13],). A temporary storage system, consisting of a set of batteries for balancing production and demand is also installed. The hydrogen is then transported to the final users by ships (barges), after compression. It has been previously shown ([14]) that Energy Management Systems are the important components in these off-grid electrolyzation facilities, to improve efficiency of the process under variable production. A simple strategy is proposed here, to connect/disconnect components, depending on the amount of energy available, the state of charge of the batteries, and the amounts of water available for the electrolyzers and the desalination system.

The process diagram in Fig. 1 presents the four main blocks of our proposal: the wave converters, the Reverse Osmosis plant, the electrolysis unit and the compression unit. After the introduction, the proposed components are described in section 2, together with the proposed sizing methodology, and some mathematical models that can be used for this sizing. In section 3, results and discussion are proposed. Finally, some conclusions are provided in section 4.

\section{Material and methods}

\subsection{Description of components}

\subsubsection{Wave converters}

The number of companies that provide devices capable of exploiting wave energy is increasing every day. The output energy of a mechanism is basically determined by the system characteristics and the wave weather in the area [15].

We assume here the use of a wave converter multibody floating WEC, for offshore installations: the energy is

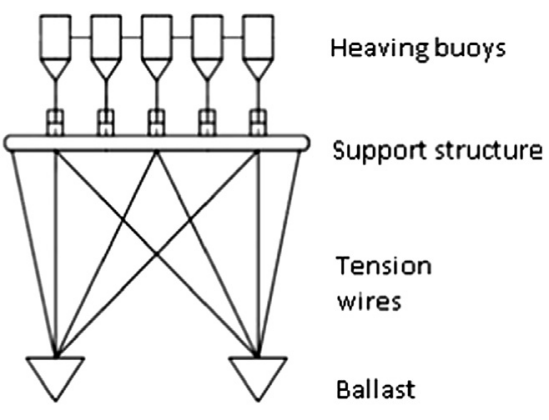

Fig. 2 - Scheme of the WEC.

extracted by the relative motion of different parts of the structure. The main advantage that these devices present is that, in deep water $(>40 \mathrm{~m}$ ), there is a greater energy potential because the waves have not yet experienced losses.

Fig. 2 depicts the Wave Converter used in this study: it is composed of a common submerged reference structure, formed by a series of ballasts baskets, and connected through tension wires. The total buoyancy force from the buoys is balanced by ballasts baskets. The buoys are connected to the submerged structure via hydraulic Power Take-Off (PTO) systems, which converts the mechanical energy into hydraulic energy, which is later converted in a turbine into electrical energy.

One of the key points in the structural design and energy extraction capacity of the device is the response to different periods and wave heights (Fig. 3).

The devices have a maximum range of operation: The energy that can be used by a device is limited to a maximum wave height and a minimum wave period.

\subsubsection{Electrolysis}

Electrolyzation is a mature, market-available technique that can operate intermittently, producing large volumes of hydrogen without greenhouse gases emissions, as long as the electricity is provided by renewable sources [16].

In this proposal we focus on PEM electrolyzers, as they have advantages in terms of safety when compared with

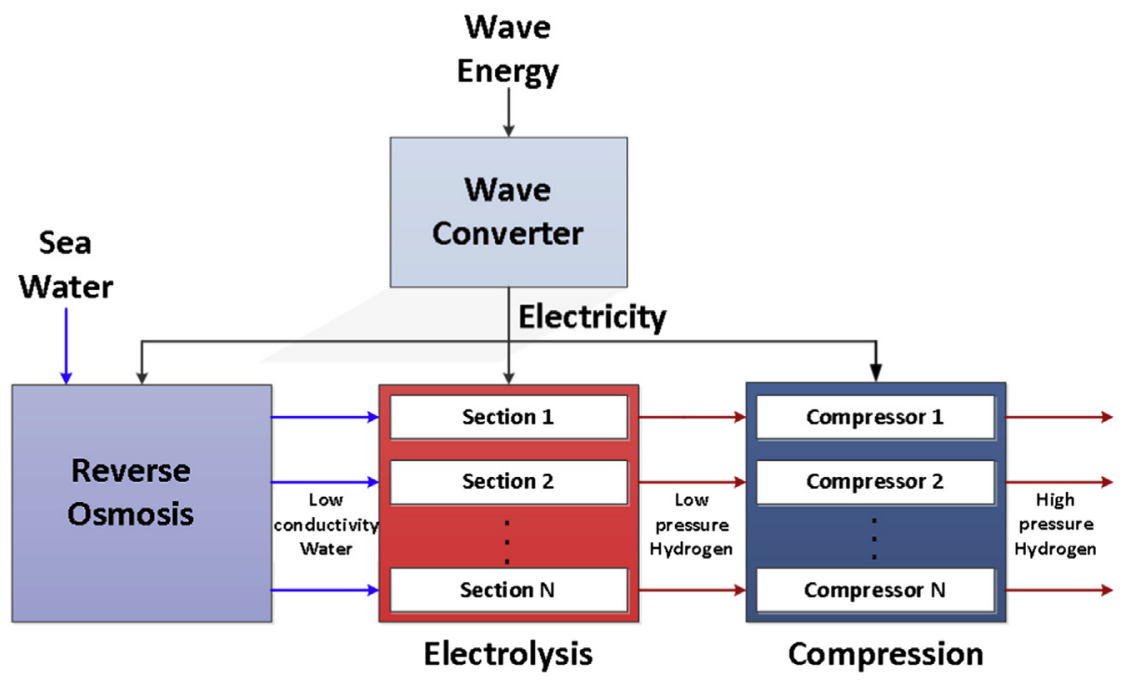

Fig. 1 - Process diagram. 


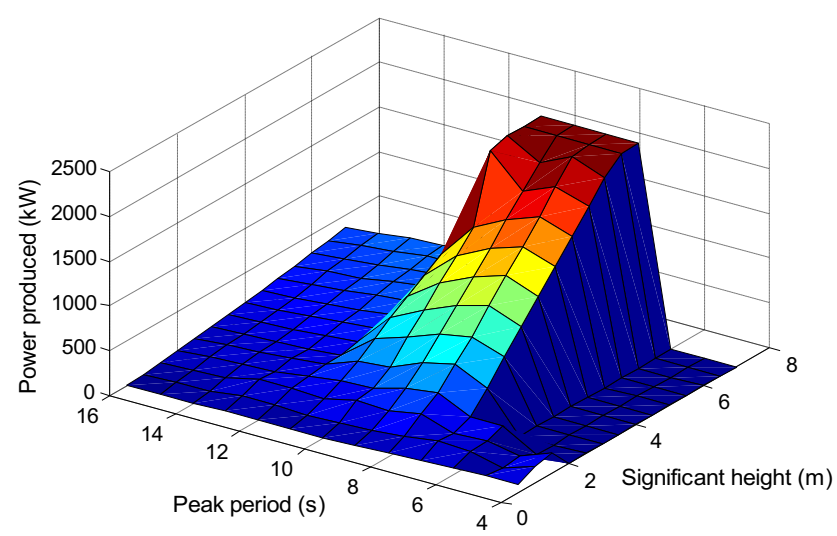

Fig. 3 - Wave converter transfer function.

alternative technologies (See [17] and references therein); moreover, they have already been successfully tested in marine environments [18]. In the case of an acidic PEM cell, it is assumed that liquid water splitting occurs according to the following half-cell reactions [19]:

anode : $\quad \mathrm{H}_{2} \mathrm{O}(\mathrm{liq}) \rightarrow 1 / 2 \mathrm{O}_{2}(\mathrm{~g})+2 \mathrm{H}^{+}+2 \mathrm{e}^{-}$

cathode : $\quad 2 \mathrm{H}^{+}+2 \mathrm{e}^{-} \rightarrow \mathrm{H}_{2}(\mathrm{~g})$

full reaction : $\mathrm{H}_{2} \mathrm{O}($ liq $) \rightarrow \mathrm{H}_{2}(\mathrm{~g})+1 / 2 \mathrm{O}_{2}(\mathrm{~g})$

Solvated protons formed at the oxygen-evolving anode of the PEM cell migrate through the membrane to the cathode where they are reduced to molecular hydrogen.

\subsubsection{Water production}

PEM electrolyzers have strict requirements in terms of the inlet water to guarantee long-term performance: ionic conductivity must be very low (in the order of a few $\mu \mathrm{S}$, with the number depending on the PEM membrane characteristics).

Taking into account the fact that the facility would be installed offshore, desalination of seawater is the natural solution; from the available desalination techniques, Reverse Osmosis (RO) is selected, as it already being used in many marine applications, it can be significantly automated, and can be easily adapted to different flow and conductivity requirements. Seawater RO water (with conductivity smaller than $5 \mu \mathrm{S}$ ) has already being used for PEM electrolyzation without a significant effect on performance [18].

RO is based on transport of water through a membrane by porosity and/or diffusion (see scheme in Fig. 4). The chemical and physical nature of the RO membrane determines its ability to allow for preferential transport of solvent (water) over solute (salt ions). To ensure water flow through the RO membrane a difference of pressure is needed between the feed and permeate sides of the membrane, that must be significantly greater than

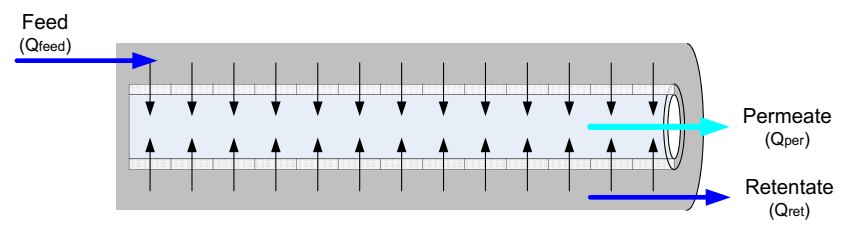

Fig. 4 - Transport of water through a RO membrane by porosity and/or diffusion. the osmotic pressure: for seawater this gives operating pressures around 60 bars [20]; the pressure at the retentate (water with salinity greater than the feed) is frequently recovered using specific devices, to improve energy efficiency.

For the proposed electrolysis application, a design such as the one in Fig. 5 is proposed, that is adapted from a previous design for automated desalination in remote areas with renewable energies (see [13] for details); however, as the energy consumption of the desalination is much smaller than that of electrolyzers, the electricity consumption of the RO plant does not need to be directly balanced with the electricity production, so operation at different flows is not needed. Thus, frequency variators and automatically control dosifiers are not included in the proposed design.

A typical concentration value of the seawater input is around $40,000 \mu \mathrm{S} / \mathrm{cm}$. There is a first stage that reduces the salt concentration to $170 \mu \mathrm{S} / \mathrm{cm}$, and a second stage to achieve a concentration of less than $2 \mu \mathrm{S} / \mathrm{cm}$, the concentration selected for the electrolyzers (other values of conductivity can be easily accommodated: the structure, energy consumption and cost of the desalination plant will not significantly vary as long as the output conductivity is in the order of a few $\mu \mathrm{S} / \mathrm{cm}$ ). One important parameter is the cost energy per $\mathrm{m}^{3}$ of water produced. In this plant, it is estimated to be about $2 \mathrm{Kwh} / \mathrm{m}^{3}$.

\subsubsection{Short-term energy storage}

The proposed system is off-grid, so energy production and demand must be constantly balanced. Several technologies have been proposed for temporarily storage (see, for example [6], for a review of technologies). In this case, as reliability is an important issue, we will assume a standard $\mathrm{Pb}$ battery rack system, as there is wide experience in marine applications.

\subsection{Control system}

A central component to ensure smooth operation of the facility is the control system that should constantly balance electricity production and consumption, by adapting the consumed loads (power of the pumps working in the reverse osmosis plant, the electrolyzers and the hydrogen compression).

It is assumed that the control system is based on the following ideas:

- When the production is higher than the consumption the energy is stored until the temporary storage system is nearly full; then sections of the electrolyzer and compression systems are switched on.

- When the storage system is almost empty sections of the electrolyzers and compression systems are switched off (these sections are then automatically cleaned and maintenance operation carried out).

- The desalination is just switched on/off depending on the amount of low-conductivity water stored in the tanks.

\subsection{Sizing}

In the proposed facility a central aspect of the design for a specific location is the selection of sizes of components, in order to ensure autonomous operation of the facility without 


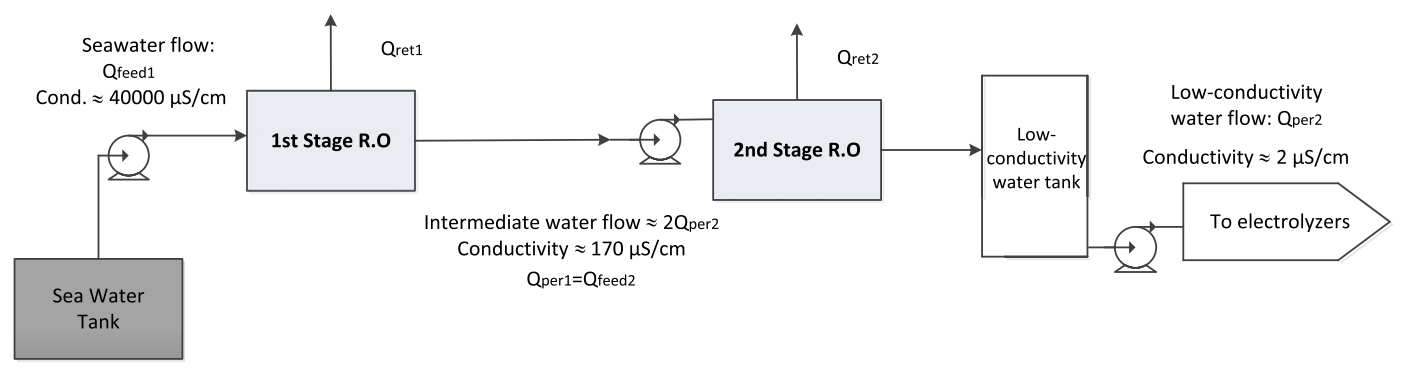

Fig. 5 - Proposed structure of the desalination system.

excessive capital or operation costs. In particular the following parameters should be selected:

- The rated power consumption of the electrolyzers $\bar{P}_{\mathrm{EL}}$ (see section 2.4.3).

- The rated flow of low-conductivity water that must be produced by the desalination plant $\mathrm{Q}_{\mathrm{per} 2}$, and the corresponding flow of inlet seawater, $Q_{\text {feed1 }}$.

- The volumes of seawater and low-conductivity water tanks ( $V_{S}$ and $V_{P}$, respectively).

- The rated battery capacity $C_{P}$.

In this kind of renewable energy installations it is important to take into account the variability of the source: for this, forecasts are usually needed. In this case, we assume that a significant record of data measured in the location where the wave converters would be placed is available (using buoys). Thus, the sizing of the proposed facility can be carried out based on the peak power $\bar{P}_{\mathrm{W}}$ of the wave converter and the measured data, by using the models that will be presented in section 2.4. As the impact of the electrolyzer investment cost on the final cost of the $\mathrm{H}_{2}$ produced is high ([21]), it has already been mentioned ([22]) that in order to reduce the production costs, not all the energy captured should be transformed into hydrogen, as this would imply huge investment costs to consume the last Watt hours. Thus, it is assumed here that the rated energy consumption of the electrolyzers is smaller than the peak production of the Wave Energy Converters: the balance would be stored temporarily in batteries (or discharged if they were fully charged).

The proposed methodology to select the plant parameters is then the following:

i. Using the measured data, the evolution of the power produced by the wave converters $P_{W}(t)$ is estimated.

ii. The rated power consumption of the electrolyzers $\bar{P}_{\mathrm{EL}}$ (see section 2.4.3), is selected to ensure that the set of electrolyzers is fully in operation for at least $\lambda \%$ of the time (this parameter would be a trade-off between the cost of the electrolyzers and the cost of the wave converters, as part of the produced energy will not be used.).

iii. The required flow of water produced by the desalination system $Q_{\text {per2 }}$ can then be calculated from the water that is required by the electrolyzers when all the set is in operation. The corresponding flow of inlet seawater $Q_{\text {feed1 }}$ can be directly calculated from the recovery ratio of the RO system. iv. The tanks volumes are selected to ensure $D_{a}$ hours of autonomy at all times.

v. The battery capacity $C_{P}$ is selected to ensure $W_{a}$ hours of autonomy at all times and DOD (see section 2.4.5) always between certain given limits.

\subsection{Modeling}

In order to carry out the proposed sizing methodology it is very important to use adequate models of the process, to predict the evolution of hydrogen production with time. Thus, some models of the components are now presented, in order to be used for estimation of the production using buoy-measured data.

\subsubsection{Wave converters model}

To evaluate the energy produced by the wave converter, waves are considered to travel along the surface of the sea with an approximate sinusoidal profile, characterized in terms of the time between successive crests and the size of these crests [23]. Wave height and period are represented by statistical measurements, the most common are the significant wave height, $H_{s}(t)$ (around four time the root-mean square of the wave height during a given window), and the wave period $T_{p}(t)$. By multiplying the wave converter transfer function (Fig. 3) with the using buoy-measured data of the sea location, the mean absorbed power during a specific time period of the device can be derived $\left(\bar{P}_{\mathrm{W}}\right)$.

\subsubsection{Desalination model}

A simplified model presented in [24] is used here, based on the complete one. The equations are similar for the two RO stages that are proposed in this paper. If a mass balance in steady state is made in the membrane inlet and outlets (see Fig. 4), the equation is:

$Q_{\text {feed1 } 1} \cdot C_{\text {feed1 }}-Q_{\text {per1 }} \cdot C_{\text {per1 }}=Q_{\text {ret } 1} \cdot \rho_{\text {ret1 }}$

where $Q_{\text {feed1 }}$ and $Q_{\text {per1 }}$ are the flow rates in the first section of the feed and the permeate, respectively, in $\mathrm{m}^{3} / \mathrm{h}, \mathrm{C}_{\text {feed } 1}$ and $C_{\text {per1 }}$ are the salt concentrations in the feed and in the permeate in $\mathrm{kg} / \mathrm{m}^{3}, \mathrm{Q}_{\text {ret1 }}$ is the salt flow, and $\rho_{\text {ret1 }}$ is the density of this flow. The flow rate of the concentrate through the membrane is defined by:

$Q_{\text {ret1 }}=B_{1} \cdot\left(C_{\text {feed1 }}-C_{\text {per1 }}\right)$

where $B_{1}$ is the membrane permeability coefficient for salt. It represents a unique constant for each membrane type, and $C_{\mathrm{feed} 1}-C_{\mathrm{per} 1}$ is the driving force for the mass transfer of salts. 
The rate of water passage through a semi-permeable membrane $\left(Q_{\text {per1 }}\right)$ is defined in equation (3).

$Q_{\text {per1 }}=A_{1} \cdot\left(p_{\text {feed } 1}-p_{\text {per1 }}-\pi_{1}\right)$

where $p_{\text {feed } 1}$ is the feed pressure, $p_{\text {per1 }}$ is the pressure in the permeate, $\pi_{1}$ is the osmotic pressure differential across the membrane, and $A_{1}$ is the membrane permeability coefficient for water. The term $A_{1}$ represents a unique constant for each membrane material type, and the terms of pressure within the parentheses is the net driving pressure or net driving force for the mass transfer of water across the membrane. The equation defining the osmotic pressure is as follows:

$\pi_{1}=\alpha \cdot\left(C_{\text {feed } 1}-C_{\text {per } 1}\right) \cdot T$

where $\alpha$ is the osmotic coefficient, and $\mathrm{T}$ is the temperature in $\mathrm{K}$.

The salinity of the permeate, $\mathrm{C}_{\text {per1 }}$, depends on the relative rates of water and salt transport through the reverse osmosis membrane, as equation (5) describes:

$C_{\text {per1 }}=\frac{Q_{\text {ret1 }}}{Q_{\text {per1 }}}$

The fact that water and salt have different mass transfer rates through a given membrane creates the phenomenon of salt rejection. No membrane is ideal, in the sense that it absolutely rejects salts; rather, the different transport rates create an apparent rejection. The equations (2) and (3) explain important design considerations in RO systems. For example, an increase in operating pressure will increase water flow without changing salt flow, thus resulting in lower permeate salinity. There must be appropriate values of concentrations at the outlet of the permeate flux, because the water electrolyzers work with very low conductivity salt ( $<2 \mu \mathrm{S} / \mathrm{cm})$.

Knowing the flow rate in the input and output of the reverse osmosis plant, the hydraulic power consumed for each pump $\left(P_{\text {hyd1 }}\right)$ can be calculated with equation (6), where $\rho_{\text {feed }}$ is the density of the flow rate and $\mathrm{H}_{1}$ is the dynamic head of the pump (that is a function of pressure [24]).

$P_{\text {hyd } 1}=\rho_{\text {feed }} \cdot g \cdot H_{1} \cdot Q_{\text {feed } 1}$

For the second section, a parallel set of equations can be easily derived, to estimate $P_{\text {hyd2 }}$.

Finally, the value of the electrical power consumed by the two pumps in the process, $P_{\mathrm{RO}}$, is obtained with equation (7).

$P_{\text {RO }}=P_{\text {hyd1 } 1} \cdot \vartheta_{\text {pump1 } 1} \cdot \vartheta_{\text {engine1 }}+P_{\text {hyd2 }} \cdot \vartheta_{\text {pump2 }} \cdot \vartheta_{\text {engine2 }}$

where $v_{x}$ are the efficiencies of pumps and their engines.

\subsubsection{Electrolyzation model}

PEM technology is one of the most promising water electrolysis technology for direct coupling with renewable electrical sources $[25,26]$. The purpose here is to use a simple PEM water electrolyzer model that predicts energy and water consumptions and hydrogen production, so a simplified electrochemical submodel will be described based on [27].

From a thermodynamic point of view, the minimum voltage to start the water electrolysis reaction corresponds to the sum of the reversible potential for each semi reaction described in 2.1.2 at both electrodes.
These minimum potentials are affected by pressure and temperature conditions of the reactions. Moreover, in real systems higher potential must be applied due to kinetics losses at the bipolar plates, electrodes and internal resistances in the cell. Hence, when current is flowing through the electrodes the operating voltage for a single cell $\left(\mathrm{V}_{\text {cell }}\right)$ is given by the reversible voltage and the sum of different over potentials. For PEM electrolytic cells:

$\mathrm{V}_{\text {cell }}=U_{\text {rev }}+\left(\eta_{a}+\eta_{a}\right)+\eta_{\Omega}$

a) Reversible voltage

The reversible voltage or open circuit voltage at the cell $\left(U_{\text {rev }}\right)$ in equation (8), depends on the temperature and pressure of reaction. This dependence can be theoretically estimated from thermodynamic calculations on the change of the Gibbs free energy or from the electrochemical point of view using the Nernst equation for water electrolysis (9). Assuming $\mathrm{H}_{2}$ and $\mathrm{O}_{2}$ as ideal gases, water as an incompressible fluid and ideal gas-liquid phases mixture can simplify the calculations of thermodynamic variables and activity coefficients $\left(a_{\mathrm{H}_{2} \mathrm{O}}, a_{\mathrm{H}_{2}}, a_{\mathrm{O}_{2}}\right)$.

$U_{\text {rev }}(T, p)=\frac{\Delta G(T)}{n F}+\frac{R T}{n F} \cdot \ln \left[\frac{a_{\mathrm{H}_{2} \mathrm{O}}}{a_{\mathrm{H}_{2}} \cdot\left(a_{\mathrm{O}_{2}}\right)^{1 / 2}}\right]$

Therefore, for low-pressure or atmospheric applications the effect of the pressure can be neglected in order to simplify the model. Reversible voltage for water electrolysis at constant atmospheric pressure is empirically given by [28]:

$U_{\text {rev }}(T)=1.5184-1.5421 \cdot 10^{-3}+9.523 \cdot 10^{-5} \mathrm{Tln} \mathrm{T}+9.84 \cdot 10^{-8} \mathrm{~T}^{2}$

\section{b) Electrodes overpotential}

When current flows through the electrolytic cell, charge transfer and mass transport phenomena in the electrode must be considered. These limitations on the semi reactions are known as activation and concentration over potentials respectively. On each electrode, one of the branches (oxidation at the anode and reduction at the cathode) will dominate during operation. Therefore, the anodic and cathodic activation over potentials ( $\eta_{a}$ and $\eta_{c}$ respectively) in equation (8) can be written as:

$\eta_{a}=\frac{R T}{\alpha_{a} z F} \cdot \ln \left(\frac{i_{a}}{i_{0, a}}\right)$

$\eta_{c}=\frac{R T}{\alpha_{c} z F} \cdot \ln \left(\frac{i_{c}}{i_{0, c}}\right)$

where $\alpha_{c}$ and $\alpha_{a}$ are defined as the charge transfer coefficients for the cathode and the anode respectively. Many reactions tend toward symmetry, so with no information available it is usual to assume both charge transfer coefficients as 0.5 . In water electrolysis $z=2$. $i_{0, a}$ and $i_{0, c}$ are the exchange current densities for each electrode. The activation overpotential is highly affected for these values, which depend on the used electrocatalyst, electrode morphology, age, pressure, temperature and other factors. 
A value of $i_{0, \text { ref }}$ at reference temperature must be chosen from literature or from manufacture's information, then:

$i_{0}=i_{0, \text { ref }} \cdot e^{\left[\frac{E_{\text {pro }}}{R}\left(\frac{1}{T}-\frac{1}{T_{\text {ref }}}\right)\right]}$

where $E_{\text {exc }}$ can be defined as the activation energy for the electrode reaction. During the global reaction, each electrode has its own contribution to the activation over potential (i.e, $\left.\eta_{\text {act }}=\eta_{\text {act,a }}+\eta_{\text {act,c }}\right)$. However this contribution is not symmetric, typically the values of the exchange current density at the anode electrode are much lower at the cathode side (e.g $10^{-7} \mathrm{~A} / \mathrm{cm}^{2}$ in $\mathrm{Pt}-\mathrm{Ir}$ anode and $10^{-3} \mathrm{~A} / \mathrm{cm}^{2}$ in Pt cathode at $80{ }^{\circ} \mathrm{C}[29]$. In this sense the cathode contribution to the activation overpotential can be neglected. At high current densities transport limitations cannot be neglected.

\section{c) Resistive overpotential}

The ohmic over potential in equation (8) could be expressed by:

$\eta_{\Omega}=\left(R_{\text {ele }}+R_{\text {ion }}\right) i=R_{\mathrm{i}} \mathrm{i}$

where $R_{\text {ele }}$ and $R_{\text {ion }}$ are the electronic and ionic contribution to the resistive losses. The addition of the two contributions can be defined as the normalized interfacial resistance $\left(R_{i}\left[\Omega \mathrm{cm}^{2}\right]\right)$.

$R_{\text {ele }}$ increases with the operation temperature, it is due to the electrical resistance of the cell components with the exception of the electrolyte (bipolar and current collector plates, gas diffusion layers, and electrode layers).

The ionic resistance of the membrane $\left(R_{\text {ion }}\right)$ is due to the resistance to the protons transport in the polymeric membrane. Thus ionic resistance can be expressed as a function of the thickness $\left(t_{m}\right)$ and the conductivity $(\sigma)$ of the membrane.

$R_{\text {ion }}=\frac{t_{m}}{\sigma}$

The temperature dependence of the membrane conductivity is modeled using an Arrhenius expression [30]:

$\sigma(T)=\sigma_{\text {ref }} \cdot e^{\left[\frac{E_{\text {pro }}}{R}\left(\frac{1}{T_{\text {ref }}}-\frac{1}{T}\right)\right]}$

where $E_{\text {pro }}$ is a temperature independent parameter which represents the activation energy for proton transport in the membrane. In practice, the main contribution to the resistive losses is expected to arise from $R_{\text {ion }}$, since conductivity of the membrane is usually much lower than conductivity of the rest of components. Thus neglecting the $R_{\text {ele }}$ contribution does not imply a significant error.

Finally, equation (17) gives the power consumed for a single cell $\left(P_{\mathrm{EL}}\right)$ where $I_{\text {cell }}$ is the current of the cell:

$\mathrm{P}_{\mathrm{EL}}=\mathrm{V}_{\text {cell }} \cdot \mathrm{I}_{\text {cell }}$

\subsubsection{Compressor model}

For real gases far above their boiling temperature, the thermodynamic process of compression can be described by the adiabatic compression equation (18):

$P_{C}=m_{\mathrm{H}_{2}} \cdot\left[\frac{\gamma}{\gamma-1}\right] \cdot p_{0} \cdot V_{0} \cdot\left[\left(\frac{p_{1}}{p_{0}}\right)^{\frac{\gamma}{\gamma-1}}-1\right]$ where $P_{C}$ is the power consumed in the compression process, $p_{0}$ the initial pressure, $p_{1}$ the final pressure, $V_{0}$ the initial specific volume, $\gamma$ the ratio of specific heats, and $m_{\mathrm{H}_{2}}$ is the hydrogen production rate $(\mathrm{kg} / \mathrm{h})$ [31].

In both isothermal and adiabatic compression, the compression work is the difference between the final and initial energy states of the gas. At identical final pressures, the different compression processes yield different temperatures of the compressed medium. In the ideal isothermal case, the temperature would remain constant, while it rises considerably under adiabatic conditions. Moreover, the compression work depends on the nature of the gas.

\subsubsection{Electricity storage model}

The batteries are used to provide energy to the reverse osmosis plant and electrolyzers when not enough power is provided by the wave converters.

$I=\frac{P_{\mathrm{W}}-P_{\mathrm{OS}}-P_{\mathrm{EL}}-P_{\mathrm{C}}}{V}$

where $I$ is the amperage of the battery, $V$ is the battery voltage and $P$ with different subscripts are the power supplied by the wave converter $\left(P_{\mathrm{W}}\right)$ and the power consumed in the reverse osmosis plant $\left(P_{\mathrm{OS}}\right)$, electrolyzers $\left(\mathrm{P}_{\mathrm{EL}}\right)$ and compression unit $\left(P_{C}\right)$. The equation relating the capacity of the battery and the amperage is as follows (20):

$\frac{\mathrm{d} C_{R}}{\mathrm{dt}}=\eta \frac{\mathrm{I}^{k}}{3600}$

where $C_{R}$ is the rated capacity at that discharge rate, $t$ the time, $k$ is Peukert's coefficient and $\eta$ is the efficiency of the battery. The key decision variable, the depth of discharge (DOD) of a battery, is the percentage of capacity to which it is discharged. Values approaching 1 correspond to the battery being almost discharged. The DOD is given by the expression below, where $C_{p}$ is Peukert's capacity.

$\mathrm{DOD}=1-\frac{C_{R}}{C_{P}}$

\section{Results and discussion}

To validate the proposed offshore hydrogen platform and the sizing methodology, a case-study was carried out for a specific location in the North Sea, selected by its good wave regime and proximity to potential hydrogen consumers. For this location, buoy data was measured for 165 days (wave heights, periods, water salinity and temperature, etc). Based on this data, a platform was designed using the proposed sizing methodology with the following parameters in the models:

- Reverse Osmosis plant: $Q_{\text {feed } 1}=11.4 \mathrm{~m}^{3} / \mathrm{h}, C_{\text {feed } 1}=18 \mathrm{~kg} / \mathrm{m}^{3}$, $B_{1}=B_{2}=0.01 \mathrm{~m}^{3} / \mathrm{h} \cdot$ bar, $A_{1}=A_{2}=0.2 \mathrm{~m}^{3} / \mathrm{h} \cdot$ bar, $p_{\text {feed } 1}=52 \mathrm{bar}$, $p_{\text {per1 }}=1.5$ bar, $\alpha=0.003$ bar $\mathrm{m}^{3} / \mathrm{Kg} \cdot \mathrm{K}, \rho_{\text {feed }}=1000 \mathrm{~kg} / \mathrm{m}^{3}$, $g=9.8 \mathrm{~m} / \mathrm{s}^{2}, \vartheta_{\text {pump } 1}=\vartheta_{\text {pump2 }}=0.54, \vartheta_{\text {engine } 1}=\vartheta_{\text {engine } 2}=0.55$.

- Electrolysis: $\mathrm{T}_{\mathrm{ref}}=320 \mathrm{~K}, \mathrm{~T}=293 \mathrm{~K}, \sigma_{\mathrm{ref}}=10000 \mathrm{~S} / \mathrm{m}, \mathrm{i}=10000 \mathrm{~A} /$ $\mathrm{m}^{2}, \mathrm{i}_{0, \text { ref }}=10 \mathrm{~A} / \mathrm{m}^{2}, E_{\text {exc }}=53990 \mathrm{~J} / \mathrm{mol}, E_{\text {pro }}=18912 \mathrm{~J} / \mathrm{mol}$, $t_{m}=0.0002 \mathrm{~m}, I_{\text {cell }}=55000 \mathrm{~A}, \mathrm{R}=8.314 \mathrm{~J} / \mathrm{mol} \cdot \mathrm{K}, \mathrm{F}=96485 \mathrm{C} /$ mol. 


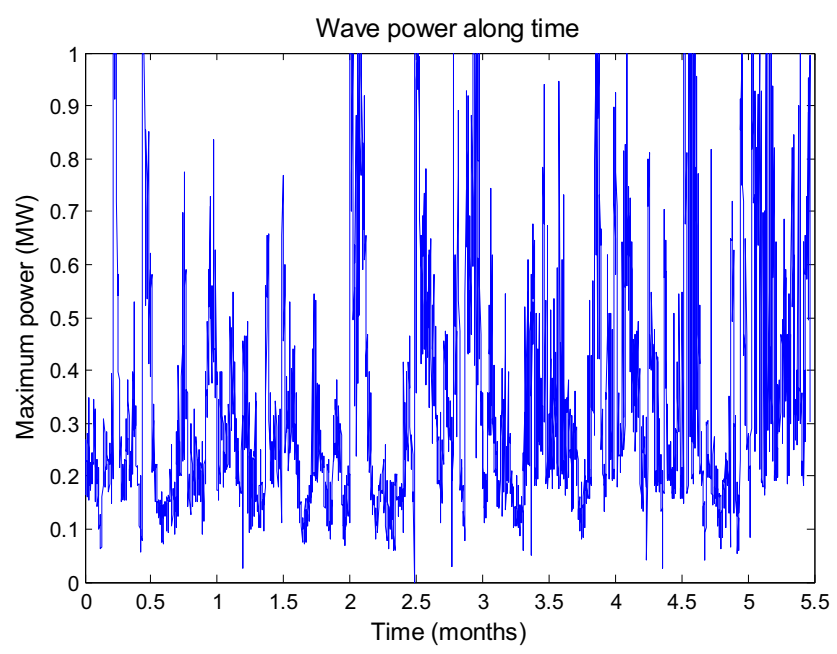

Fig. 6 - Converted power along time.

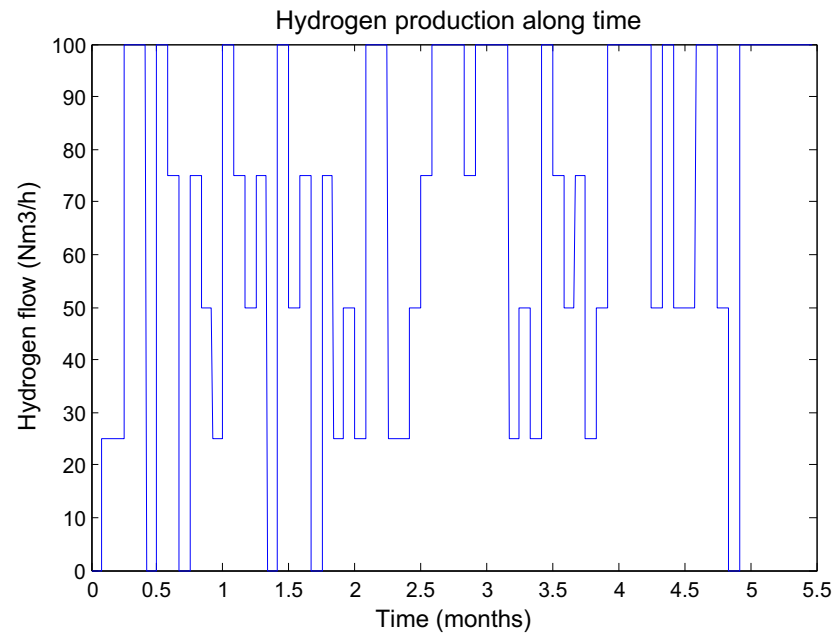

Fig. 7 - Hydrogen production along time.

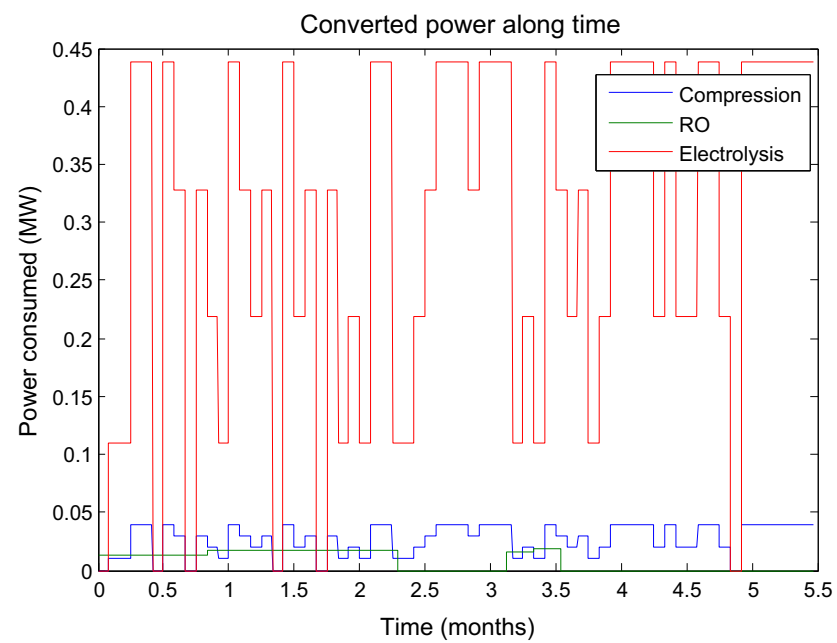

Fig. 8 - Power consumed along time.

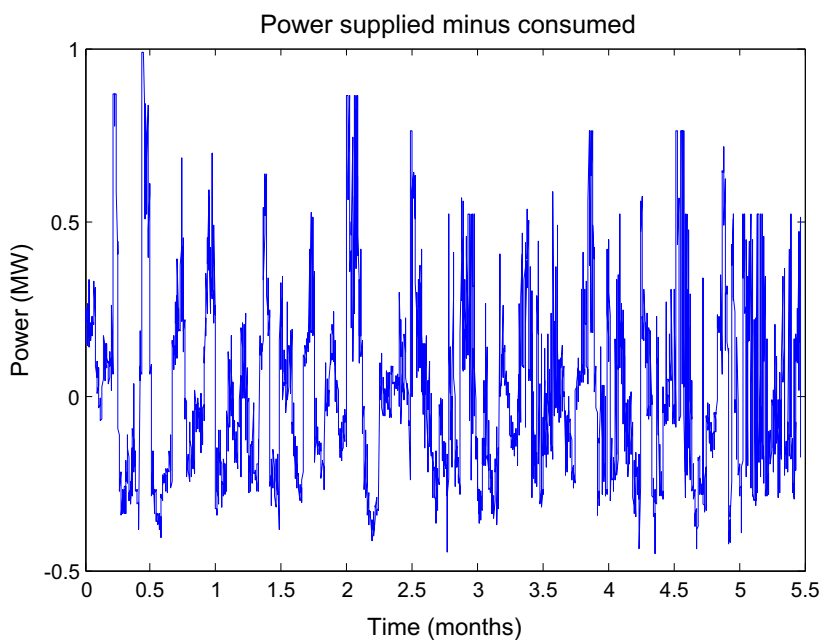

Fig. 9 - Power balance.

- Compression: $\gamma=1.41, \mathrm{~V}_{0}=11.1 \mathrm{~m}^{3} / \mathrm{kg}, p_{0}=1 \mathrm{bar}$, $p_{1}=200$ bar.

- Batteries: $\mathrm{V}=12 \mathrm{~V}, k=1.12, \eta=0.9$.

Based on the measurements and these parameters, the results of the sizing of the components following the procedure proposal in section 2.3 are the following:

- $\overline{\mathrm{P}}_{\mathrm{EL}}=0.44 \mathrm{MW}$.

- $Q_{\text {feed } 1}=11.4 \mathrm{~m}^{3} / \mathrm{h}$.

- $Q_{\text {per2 }}=0.066 \mathrm{~m}^{3} / \mathrm{h}$.

- $\mathrm{V}_{\mathrm{S}}=45 \mathrm{~m}^{3}$.

- $\mathrm{V}_{\mathrm{p}}=1 \mathrm{~m}^{3}$.

- $\mathrm{C}_{p}=3000 \mathrm{Ah}(15 \cdot 200 \mathrm{Ah})$

Figs. 6-11 show the expected operation for the nominal parameters on 165 days with buoy measurements. It can be seen that the proposed system operates adequately:

- As can be seen in Fig. 6, the value of power provided by the wave converter varies between 0 and $1 \mathrm{MW}$ due to the uniqueness of the wave conditions.

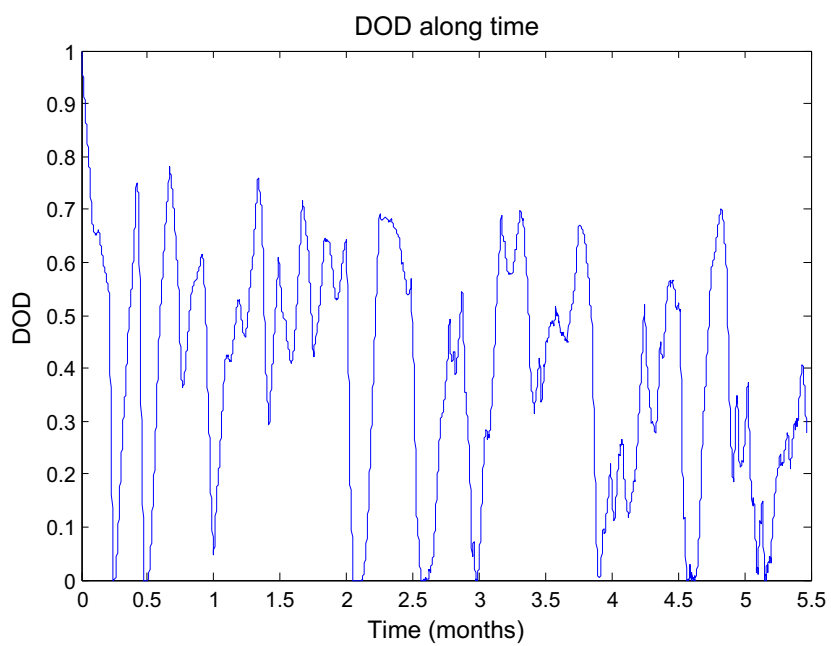

Fig. 10 - Evolution of the depth-of-discharge of the battery. 


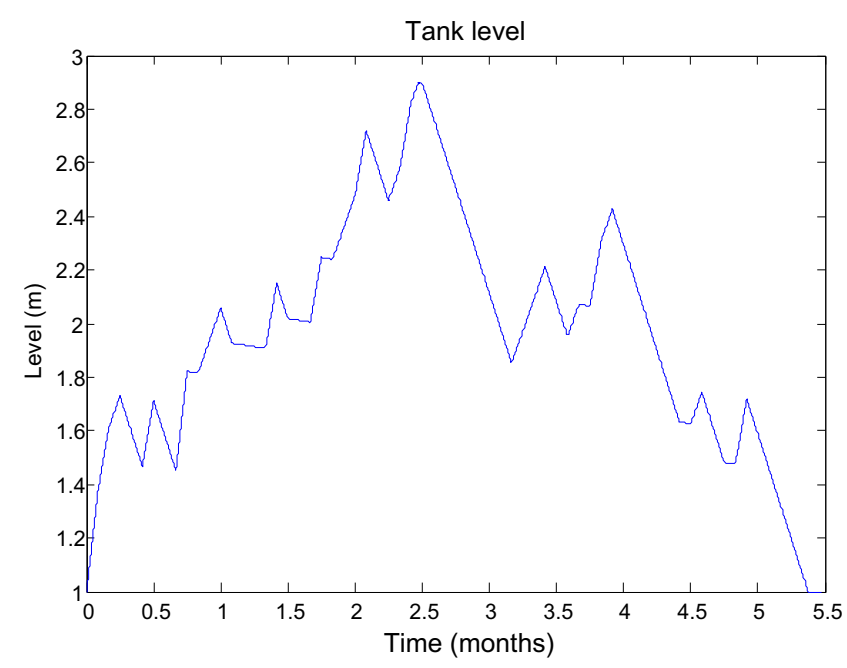

Fig. 11 - Low conductivity tank level.

\begin{tabular}{|c|c|c|c|}
\hline $\begin{array}{l}\mathrm{H}_{2} \text { produced } \\
\left(\mathrm{Nm}^{3}\right)\end{array}$ & $\begin{array}{cc}\text { Energy } & \text { Energy } \\
\text { consumed } & \text { produced } \\
\text { in electrolysis } & \text { by WEC } \\
(\mathrm{MWh}) & \text { (MWh) }\end{array}$ & $\begin{array}{c}\text { Fresh } \\
\text { water } \\
\text { produced } \\
\left(\mathrm{m}^{3}\right)\end{array}$ & $\begin{array}{c}\text { Seawater } \\
\text { consumed } \\
\left(\mathrm{m}^{3}\right)\end{array}$ \\
\hline 262,000 & 1336 & 260 & 45,030 \\
\hline
\end{tabular}

- Fig. 7 shows the flow of hydrogen produced: it can be seen that the proposed controller adapts production to the available energy.

- Fig. 8 depicts the used power. As expected, the electrolysis process consumes most of the power (four sections of $110 \mathrm{~kW}$ were assumed); compression consumes between 10 and $40 \mathrm{~kW}$ and RO consumes $20 \mathrm{~kW}$ when it is connected.

- It can be seen in Fig. 9 the power balance of the plant (power supplied minus power consumed).

- The battery's Depth of Discharge (DOD) changes along time as depicted in Fig. 10: it evolves between the required range, without fully discharging or overcharging (which is known to significantly decrease battery life).

- Finally, Fig. 11 depicts the amount of low-conductivity water stored.

Table 1 summarizes the total parameters and consumptions. This corresponds to a mean production of $1595 \mathrm{Nm}^{3} \mathrm{H}_{2}$ / day, consuming $4.2 \mathrm{kWh} / \mathrm{Nm}^{3} \mathrm{H}_{2}$ (that conforms to the $4.3 \mathrm{kWh} /$ $\mathrm{Nm}^{3} \mathrm{H}_{2}$ reported in [21]): $88 \%$ is used in the electrolyzers, $9 \%$ in compression and 3\% for desalination and other uses.

\section{Conclusions}

A proposal for using wave energy to produce hydrogen in offshore plants is studied in this paper, based on a system completely isolated from the electrical grid, so a grid independent system is used, based on adapting power consumption to power production by connecting or disconnecting sections of the electrolyzation plant, and using a temporary storage of electricity for short-time balances. After presenting the proposal design of the facility, which consists of a desalination system, PEM electrolyzers and hydrogen compression, a controller has been proposed, and some guidelines for sizing the plant for specific locations have been given.

These sizing is based on using buoy data at the proposed location, and a multi-component model-based simulation, which makes possible to reproduce the effect of measured sea conditions (height or wave period) on the hydrogen production.

To demonstrate the feasibility of the proposed platform, this proposal has been evaluated for one specific location, using buoy-measured data for sizing the proposed platform at this location. The selected design was then evaluated in terms of hydrogen production and evolution of the platform parameters, showing how the proposed design methodology makes possible to produce hydrogen in a sustainable way.

\section{Acknowledgments}

This work was partly supported by MiCInn (DPI2010-21589c05-05) and the European Commission (7th Framework Programme, grant agreement 288145, Ocean of Tomorrow Joint Call 2011). We also acknowledge GRUPO SETA for designing the Reverse Osmosis system and the Marine Institute of Ireland for collaboration in buoy measurements.

\section{R E F E R E N C E S}

[1] Bockris JO'M, Veziroglu TN, Smith D. Solar hydrogen energy: the power to save the earth. London: Optima; 1991.

[2] Sherif SA, Barbir F, Veziroglu TN. Wind energy and the hydrogen economy-review of the technology. Solar Energy 2005;78:647-60.

[3] Dutton AG, Bleijs JAM, Dienhart H, Falchetta M, Hug W, Prischich D, et al. Experience in the design, sizing, economics, and implementation of autonomous windpowered hydrogen production systems. International Journal of Hydrogen Energy 2000;25:705-22.

[4] Ghribi D, Khelifa A, Diaf S, Belhamel M. Study of hydrogen production system by using PV solar energy and PEM electrolyser in Algeria. International Journal of Hydrogen Energy 2013;38(20):8480-90.

[5] Joshi AS, Dincer I, Reddy BV. Solar hydrogen production: a comparative performance assessment. International Journal of Hydrogen Energy 2011;36:11246-57.

[6] Antonia O, Saur G. Wind to hydrogen in California: case study, national renewable energy laboratory. Technical Report NREL/TP 20125600-53045.

[7] Clément A, McCullen P, Falcão A, Fiorentino A, Gardner F, Hammarlund $\mathrm{K}$, et al. Wave energy in Europe: current status and perspectives. Renewable and Sustainable Energy Reviews 2002;6(5):405-31.

[8] Temeev AA, Belokopytov VP, Temeev SA. An integrated system of the floating wave energy converter and electrolytic hydrogen producer. Renewable Energy 2006;31(2):225-39.

[9] Morse AP. U.S. Patent No. 7872363. Washington, DC: U.S. Patent and Trademark Office; 2011. 
[10] Morse AP. U.S. Patent No. 7228812. Washington, DC: U.S. Patent and Trademark Office; 2007.

[11] Stoutenburg ED, Jenkins N, Jacobson MZ. Power output variations of co-located offshore wind turbines and wave energy converters in California. Renewable Energy 2010;35:2781-91.

[12] Jovcic D, Strachan N. Offshore wind farm with centralised power conversion and DC interconnection. IET. Generation, Transmission \& Distribution 2009;3(6):586-95.

[13] Palacin LG, Tadeo F, de Prada C, Elfil H, Salazar J. Operation of desalination plants using hybrid control. Desalination and Water Treatment, DWT 728025:119-26.

[14] Ziogou C, Ipsakis D, Seferlis P, Bezergianni S, Papadopoulou S, Voutetakis S. Optimal production of renewable hydrogen based on an efficient energy management strategy. Energy 2013 [in press].

[15] Babarit A, Hals J, Muliawan MJ, Kurniawan A, Moan T, Krokstad J. Numerical bencharking study of a selection of wave energy converters. Renewable Energy 2012;45:44-63.

[16] Mansilla C, Louyrette J, Albou S, Bourasseau C, Dautremont S. Economic competitiveness of off-peak hydrogen production today-A European comparison. Energy 2013 [in press].

[17] Siracusano S, Baglio V, Briguglio N, Brunaccini G, Di Blasi A, Stassi A, et al. An electrochemical study of a PEM stack for water electrolysis. International Journal of Hydrogen Energy 2012;37:1939-46.

[18] Di Blasi A, Andaloro L, Siracusano S, Briguglio N, Brunaccini G, Stassi A, et al. Evaluation of materials and components degradation of a PEM electrolyzer for marine applications. International Journal of Hydrogen Energy 2013;38(18):7612-5.

[19] Millet P, Dragoea D, Grigoriev S, Fateevb V, Etievant C. GenHyPEM: a research program on PEM water electrolysis supported by the European Commission. International Journal of Hydrogen Energy 2010;34:4974-82.

[20] Wilf M. The guidebook to membrane desalination technology. L'Aquila, Italy: Balaban Desalination Publication; 2007.
[21] Mansilla C, Dautremont S, Shoai Tehrani B, Cotin G, Avril S, Burkhalter E. Reducing the hydrogen production cost by operating alkaline electrolysis as a discontinuous process in the French market context. International Journal of Hydrogen Energy 2011;36(11):6407-13.

[22] Troncoso E, Newborough M. Electrolysers for mitigating wind curtailment and producing 'green' merchant hydrogen. International Journal of Hydrogen Energy 2011;36(1):120-34.

[23] Thorpe TW. A brief review of wave energy. A report produced for the UK department of trade and industry. ETSU-R120:2425. Harwell, UK 1999.

[24] Syafiie S, Palacin L, de Prada C, Tadeo F. Membrane modeling for simulation and control of reverse osmosis in desalination plants. In: Proceedings of the UKACC International Conference on control 2008.

[25] Millet P, Ngameni R, Grigoriev S, Mbemba N, Brisset F, Ranjbari A, et al. PEM water electrolyzers: from electrocatalysis to stack development. International Journal of Hydrogen Energy 2010;35:5043-52.

[26] Millet P, Mbemba N, Grigoriev S, Fateev V, Aukauloo A, Etievant C. Electrochemical performances of PEM water electrolysis cells and perspectives. International Journal of Hydrogen Energy 2011;36:4134-42.

[27] García-Valverde A, Espinosa N, Urbina A. Optimized method for photovoltaic-water electrolyser direct coupling. International Journal of Hydrogen Energy 2011;36:10574-86.

[28] Roy A, Watson S, Infield D. Comparison of electrical energy efficiency of atmospheric and high-pressure electrolysers. International Journal of Hydrogen Energy 2006;31(14):1964-79.

[29] Choi P, Bessarabovb DG, Datta R. A simple model for solid polymer electrolyte (SPE) water electrolysis. Solid State Ionics 2004;175:535-9.

[30] Nguyen TV. A water and heat management model for proton-exchange-membrane fuel cells. Journal of Electrochemical Society 1993;140(8):2178-86.

[31] Bossel U. Does a hydrogen economy make sense? Proceedings of the IEEE 2006;94(10):3-4. 